\title{
Rock-Quality Study at Tunnel Site in the Kameng Hydro-Electric Project, Bichom, Arunachal Pradesh, India
}

\author{
Mintu Kumar Kalita and Mrinal Kumar Dutta \\ Jorhat Engineering College, Jorhat, India \\ Email: mintukalita91@gmail.com; mrinaldk@rediffmail.com
}

\begin{abstract}
An idea of the rocks and general geology in the tunnel site is an important basis for developing more effective tunnel design and construction decision support systems to avoid adverse and unforeseen geological conditions in the construction of a tunnel. The main classification systems for rock support estimates, the Q and the RMR, use the most important ground features or parameters as input. The Kameng Hydro-Electric Project (KaHEP) situated in West Kameng district of Arunachal Pradesh is going to use tunnel for channelling the water collected in the reservoir of upstream of Bichom Dam to the powerhouse located at Kimi. An attempt has been made to study different geological parameters, such as Rock Quality Designation (RQD), Rock mass Quality (Q) and Rock Mass Rating (RMR) to classify the rock mass, estimate the stand-up time and to select the support systems. The rock types of the study area comprise mainly of highly fractured quartzite with shear and sericite schist and carbonaceous schist alteration. The stand-up time of the tunnel is very less as the rock mass quality is very poor and poor respectively so it requires immediate support after excavation
\end{abstract}

Keywords: KaHEP, Rock-mass, classification, RQD, Q, RMR, support system.

\section{Introduction}

There are many challenges related to long tunnels and several aspects must be thoroughly evaluated before construction. An aspect of major importance and that is decisive for the feasibility of a tunnel project is geological conditions, construction time, cost and safety. The work must be completed in a safe way resulting in minimal disturbance to the environment.

Adverse geological conditions commonly encountered in long and deep tunnels are often difficult to predict due to the limited access to the tunnel level before beginning of excavation. If such geological conditions are encountered and not secured sufficiently by means of rock support, it might lead to severe instability causing an insecure tunnel environment both during the construction phase and operational phase. In addition to bring a certain risk to tunnel projects, geological conditions are highly influencing construction time and costs. Basically, constructing a long tunnel is time consuming and very expensive process. Adverse tunnelling conditions will further enhance the costs and construction time owing to increased need for rock support at places.

The Kameng Hydro-Electric Project is run of the river scheme, situated in West Kameng district of Arunachal Pradesh. The proposed structure of the project is located between $90^{\circ} 37^{\prime} \mathrm{E}$ and $92^{\circ} 41^{\prime} \mathrm{E}$ longitudes and $27^{\circ} 10^{\prime} \mathrm{N}$ and $27^{\circ} 18^{\prime} \mathrm{N}$ latitudes (Fig. 1). This 
project includes construction of dams on two tributaries of Kameng River, Bichom and Tenga River, situated at West-Kameng District (Fig.1). The water will be diverted to powergeneration station, which is being constructed in Kimi Village; with a Head Race Tunnel from Bichom Dam. The water will be then released to Kameng River.

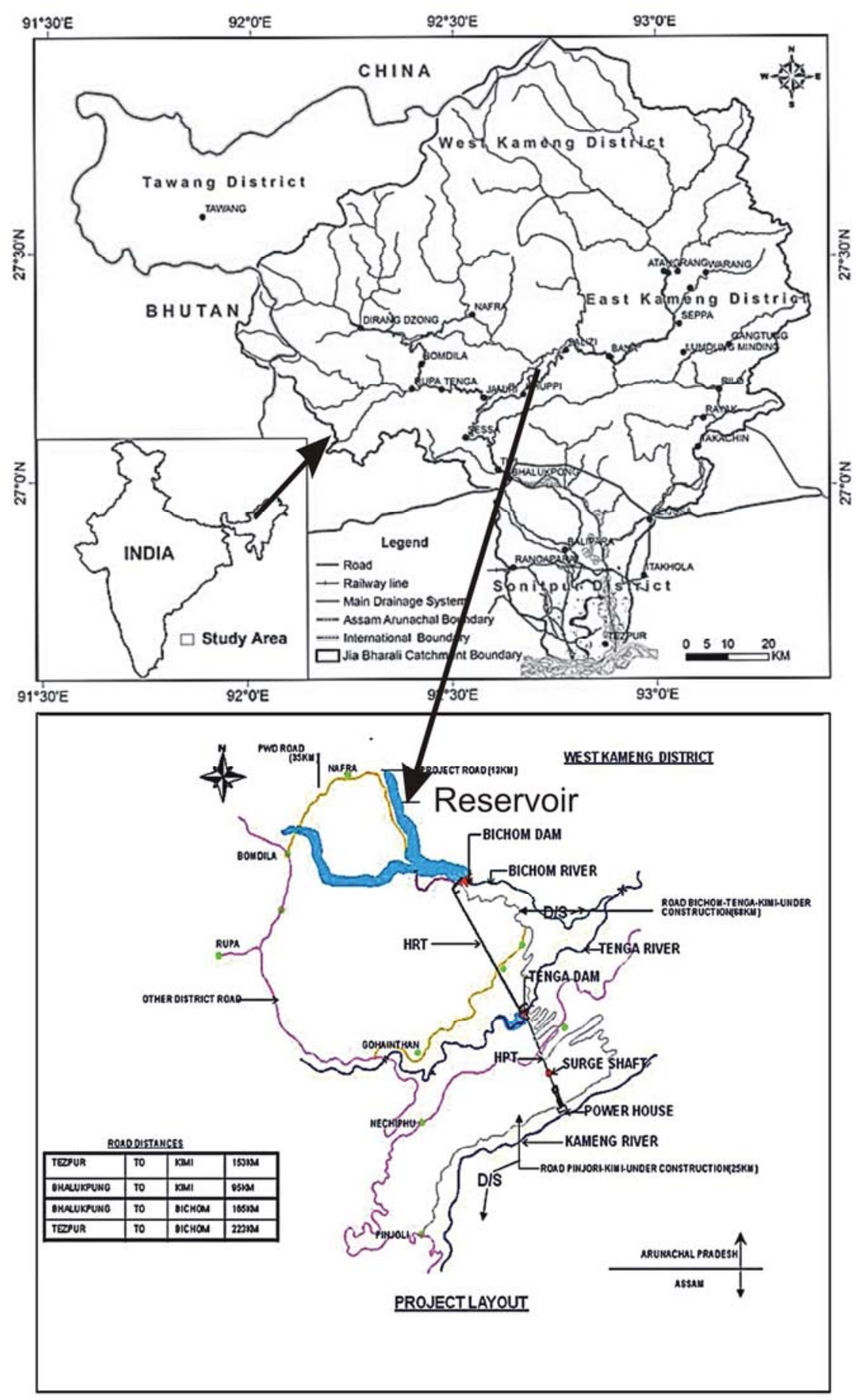

Fig. 1: Location map of the study area. 
Open access e-Journal

Earth Science India, eISSN: $0974-8350$

Vol. 9 (I), January, 2016, pp. 21 - 28

http://www.earthscienceindia.info/

\section{Methodology}

The study was undertaken with the objectives of study the different geological parameters considered for the construction of the tunnel in Kameng hydro-electric project at Bichom in Arunachal Pradesh. Attempts have been made to observe and study the rock mass for about 600meter length in the tunnel site from Adit-1 along Face-2 (Fig. 2).To analyse the existing situation in a detailed manner the area has been divided into different blocks at an interval of 1.5-2.0 m. In the field discontinuities (joints) of the rocks are observed to find out the number of joint sets present in one cubic meter of rock and their spacing and conditions of joints. Compressive strengths of the rocks have been determined in the field by Schmidt rebound hammer.

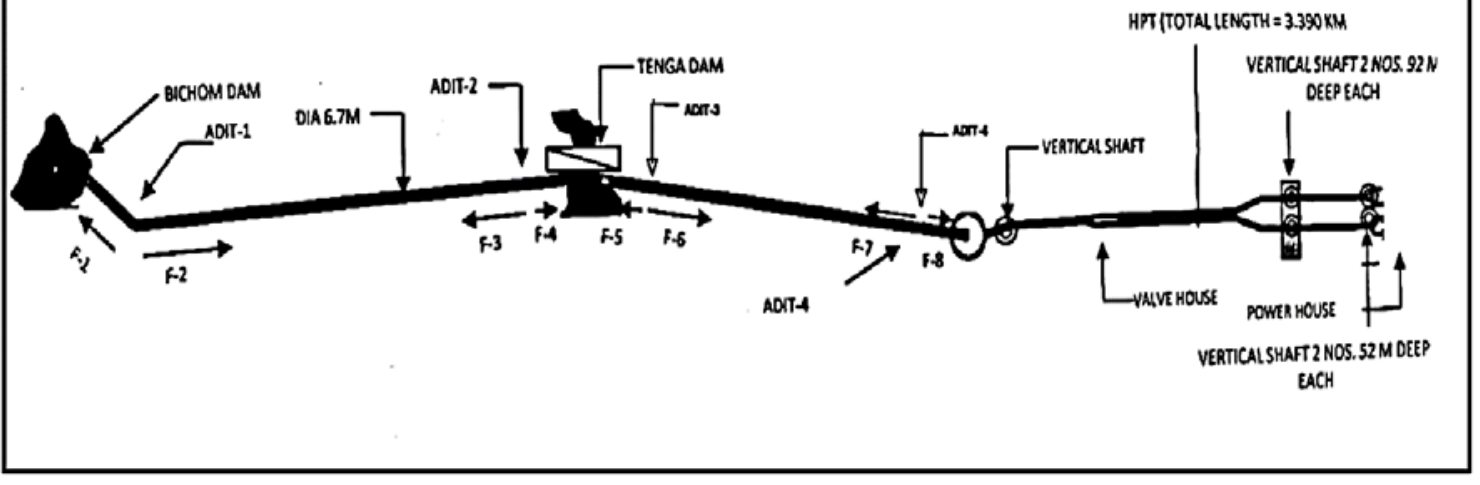

Fig 2: Layout of HRT, KaHEP.

The value of RQD, Q, and RMR has been calculated from the data collected in the field. The calculations for one representative block of the study area are shown below and the calculations of the other blocks have been made by similar method. The calculated values are used for the classification of rock mass.

\section{RQD Calculation:}

Spacing of joints: (i) 5-10cm (avg. $0.075 \mathrm{~m}$ )

(ii) $10-20 \mathrm{~cm}($ avg. $0.15 \mathrm{~m})$

(iii) $10-20 \mathrm{~cm}($ avg. $0.15 \mathrm{~m})$

$J_{\mathrm{v}}=1 / 0.075+1 / 0.15+1 / 0.15=26.67$

$\mathrm{RQD}=115-3.3 \mathrm{~J}_{\mathrm{v}}=115-3.3 \times 26.67=27 \%$ 


\section{Q-Value Calculation:}

$\mathrm{Q}=\left(\mathrm{RQD} / \mathrm{J}_{\mathrm{n}}\right) \times\left(\mathrm{J}_{\mathrm{r}} / \mathrm{J}_{\mathrm{a}}\right) \times\left(\mathrm{J}_{\mathrm{w}} / \mathrm{SRF}\right)=27 / 9 \times 2 / 4 \times 1 / 5=0.3$

Where, RQD has been calculated and the values of $\mathrm{J}_{\mathrm{n}}, \mathrm{J}_{\mathrm{r}}, \mathrm{J}_{\mathrm{a}}, \mathrm{J}_{\mathrm{w}}$ and SRF have considered based on the field conditions of joints using tables given by Barton et al. (1974).

\section{RMR-Calculation:}

Table-1: Calculations for RMR.

\begin{tabular}{|c|c|c|c|}
\hline Parameters & Value & Rating & Remarks \\
\hline Compressive strength (MPa) & $25-50$ & 4 & \multirow{7}{*}{$\begin{array}{l}\text { Standard tables given by } \\
\text { Bieniawski (1979) have } \\
\text { been used for obtaining } \\
\text { rating form the value. }\end{array}$} \\
\hline RQD & $25-50$ & 8 & \\
\hline Joint spacing ( $\mathrm{cm}$ ) & $5-10$ & 5 & \\
\hline Joint condition & $\begin{array}{l}1-5 \mathrm{~mm} \text { wide with } \\
\text { clay coating }\end{array}$ & 10 & \\
\hline Ground water condition & Dry & 15 & \\
\hline Orientation of joints & Very unfavourable & -12 & \\
\hline RMR & & 30 & \\
\hline
\end{tabular}

\section{Observation and Discussion}

The rock types of the study area mainly comprise dominantly of weak to medium strong, iron stained, fractured, foliated quartzite, sericite schist and carbonaceous schist alteration. The spacing of the foliation is $2-5 \mathrm{~cm}$ in average while in some stretches it is more than $5 \mathrm{~cm}$. Three prominent sets of joints have been recorded in the study area. Foliation is the persistent joint noticed in the area while joint set J-2 is more vulnerable to stability. Joint set $\mathrm{J}-1$ is opposite to foliation direction. Since in majority of the blocks foliation is the prominent joint having a thickness of $2-5 \mathrm{~cm}$, the RQD had been derived as $<25 \%$. In some locations shears of variable dimensions has been recorded. The thickness of the shears varies from $5 \mathrm{~cm}$ to $30 \mathrm{~cm}$. Shears are both foliation parallel and oblique to the foliation plane and comprises of crushed and pulverized rock/rock flour with clay seam.

The values of RQD, Q and RMR of some representative blocks of rock mass have been tabulated (Table-2).

The calculated value of RQD of the rock mass in the study area falls within the range $10-40 \%$ which indicates that rock mass belong to poor $(25-50 \%)$ and very poor $(<25 \%)$ categories.

Rock Mass Quality $(Q)$ is a very important classification system for the determination of rock mass characteristics and tunnel support requirements. The numerical value of the index $Q$ varies on a logarithmic scale from 0.001 to a maximum of 1,000 . The value of $Q$ of the study area lies in the range of 0.01-0.1 and 0.1-1 (Table-2) which verifies that the rock mass is extremely poor and very poor. 
Open access e-Journal

Earth Science India, eISSN: $0974-8350$

Vol. 9 (I), January, 2016, pp. 21 - 28

http://www.earthscienceindia.info/

Table-2: Values of RQD, Q\& RMR of some representative blocks

\begin{tabular}{|l|l|l|l|}
\hline $\begin{array}{l}\text { Sl. } \\
\text { No. }\end{array}$ & ROD (\%) & Q & RMR \\
\hline 1 & 27 & 0.3 & 30 \\
\hline 2 & 10 & 0.15 & 23 \\
\hline 3 & 28 & 0.1 & 22 \\
\hline 4 & 38 & 0.19 & 28 \\
\hline 5 & 11 & 0.05 & 25 \\
\hline 6 & 11 & 0.09 & 23 \\
\hline 7 & 38 & 0.16 & 30 \\
\hline 8 & 11 & 0.12 & 25 \\
\hline 9 & 40 & 0.33 & 30 \\
\hline 10 & 11 & 0.04 & 20 \\
\hline 11 & 11 & 0.04 & 20 \\
\hline 12 & 33 & 0.05 & 23 \\
\hline 13 & 27 & 0.04 & 25 \\
\hline 14 & 27 & 0.04 & 30 \\
\hline 15 & 27 & 0.04 & 25 \\
\hline
\end{tabular}

The rock mass rating (RMR) is the algebraic sum of rating of all the parameters given in Table-2. On the basis of RMR values, the rock mass is classified in five classes (IS 13365 (Part 1): 1998) and named as very good (RMR 100-81), Good (80-61), Fair (60-41), Poor $(40-21)$ and very poor $(\mathrm{RMR}<20)$. Comparing the value of RMR (Table-2) of the study area the rock mass has been classified as very poor and poor.

Application of RMR and Q: The Calculation of RMR helps in finding the average stand up time of the tunnel during excavation. Engineers must consider the type of support, its strength, and how soon it must be installed after excavation. The key factor in timing support installation is so called stand-up time i.e., how long the ground will safely stand by itself at the heading, thus providing a period for installing supports and whereas the Q-value helps in providing the support system.

By putting the estimated RMR (Table-2) value against the roof span in graph given Bieniawski,1989 as shown in the Fig 3 below, it is found that the RMR values falls in the immediate collapse zone so its requires immediate support after excavation.

Support systems: As the quality of the rock mass is found to be very poor and poor from the observation, it is recommended (Bieniawski, 1989), that the length of systematic bolt for poor rock mass should be of 4-5 m long, spaced 1-1.5 $\mathrm{m}$ in crown and wall with wire mesh and for very poor rock mass systematic bolt should be of 5-6m long, spaced 1-1.5 m in crown and wall with wire mesh. It is also recommended that for support in poor rock mass shotcrete should be $100-150 \mathrm{~mm}$ in crown and $100 \mathrm{~mm}$ in sides and light to medium steel ribs spaced $1.5 \mathrm{~m}$ should be provided. For very poor rock shotcrete should be 150-200 mm in crown and 
$150 \mathrm{~mm}$ in sides and $50 \mathrm{~mm}$ on face and medium to heavy steel ribs spaced $0.75 \mathrm{~m}$ with steel lagging and fore poling if required should be provided.

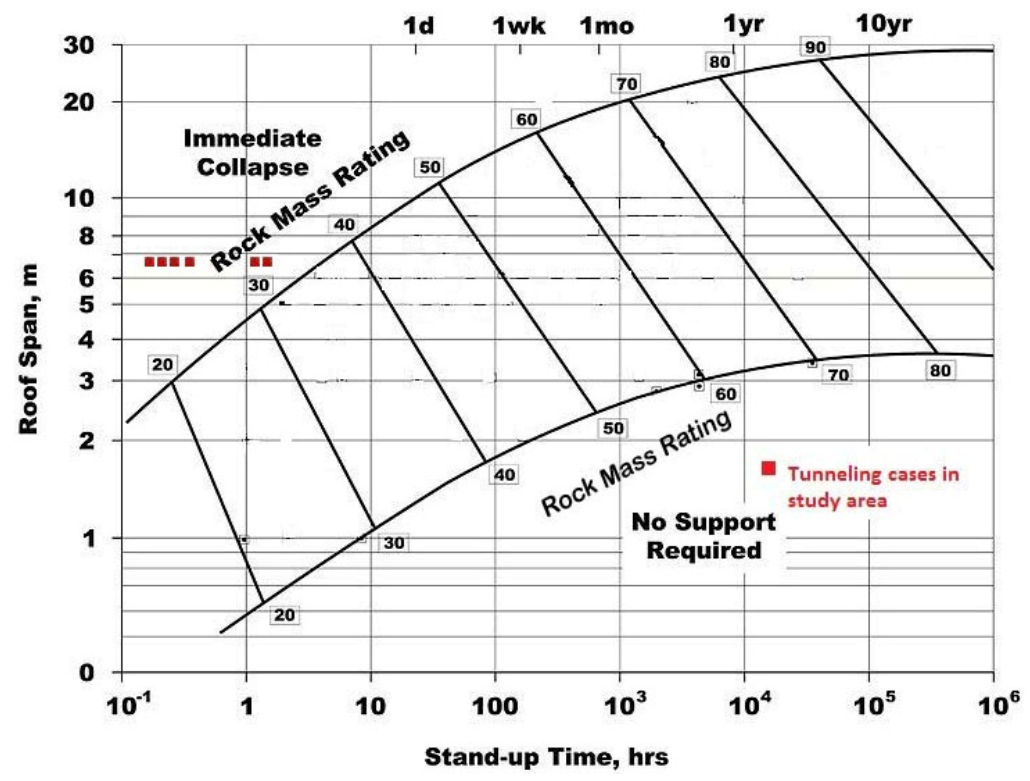

Fig 3: Stand-up time vs roof span for various rock classes as per geomechanics classification (Bieniawski, 1989)

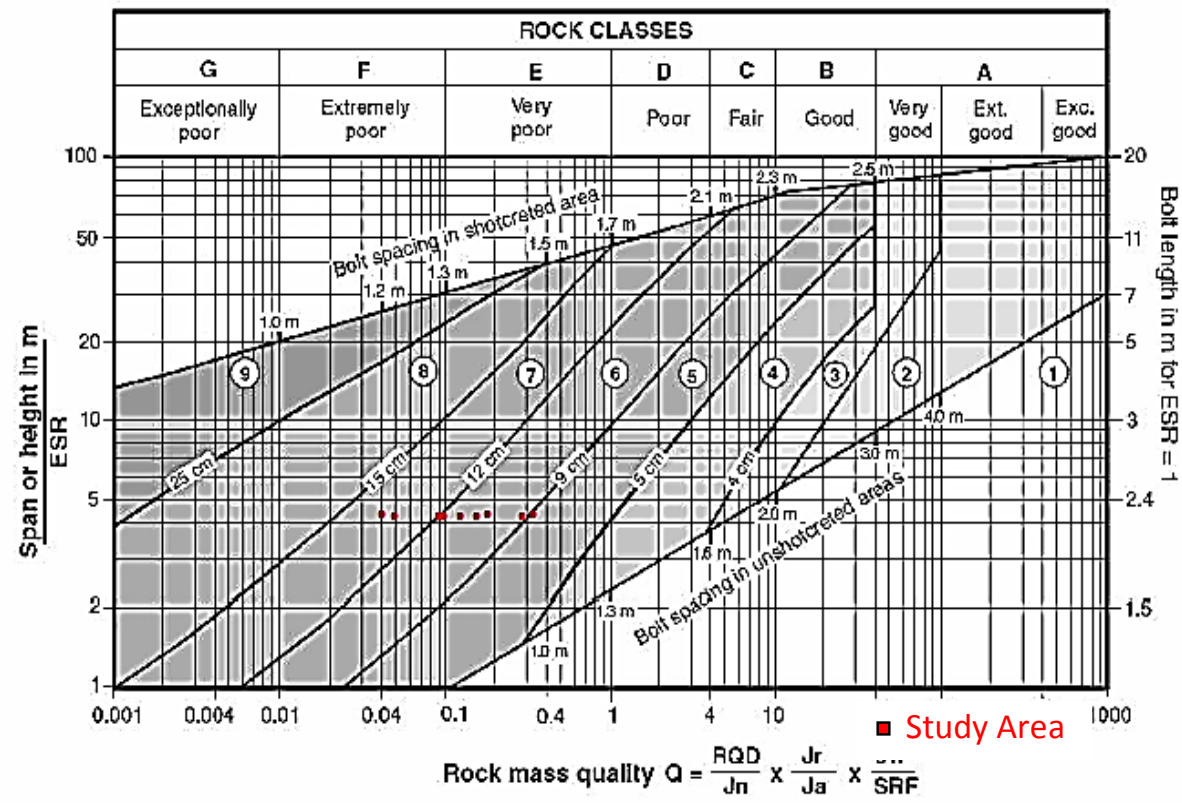

REINFORCEMENT CATEGORIES:

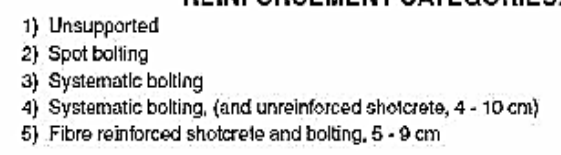

6) Fibre reinfoxced shotcrete and bolting, $9-12 \mathrm{~cm}$

7) Flbre teintoxeed shotctele and boltling, $12-15 \mathrm{~cm}$

8) Fibre telnfoxced shotcrete, $>15 \mathrm{~cm}$,

reinforced ribe of shotcrete and boling

9) Cast concrete lining

Fig. 4: Plotting of Q-values of the study area in chart for the design of steel fibre reinforced shotcrete (SRFS) support (Grimstad and Barton, 1993). 
Open access e-Journal

Earth Science India, eISSN: $0974-8350$

Vol. 9 (I), January, 2016, pp. 21 - 28

http://www.earthscienceindia.info/

By putting the calculated Q value (Table-2) in the chart (Fig. 4) given by Barton, (1993) for providing reinforcement it has been observed that the rock mass falls in the very poor and extremely poor category. Considering the span of tunnel $(6.7 \mathrm{~m})$ and values of excavation support ratio, ESR (Barton et al., 1974), it has been found that the reinforcement category should be fibre reinforced shotcrete and bolting of $9-15 \mathrm{~cm}$ length and the required bolt spacing is $1.2 \mathrm{~m}$ to $1.5 \mathrm{~m}$.

\section{Conclusion}

Evaluating rock mass quality and potential geological challenges are of major concern during the planning stage of a tunnel. The condition of the geological formations which the tunnel must pierce will be decisive for the rock support concept and construction time and it will influence construction costs. The rock types of the study area mainly comprise of highly fractured quartzite with shear and sericite schist and carbonaceous schist alteration. The shears basically comprise of crushed and pulverised rock material/rock flour with clay gauge between 2-10 cm thick. Affected zones range between 5-20 cm. Though Quartzite in general is hard but due to shearing and brittle behaviour of the rock mass, it exhibits highly fractured nature. From the study it has been observed that the quality of rock mass is not satisfactory as the rock mass quality is very poor and poor respectively which are also supplemented by the calculated value of RQD, Q and RMR. From the observation it is clearly seen that the calculated RMR values lies in the immediate collapse zone (Fig. 3) so it requires immediate support after excavation as the stand-up time of the tunnel is very less. It is also observed that the calculate Q-values also falls in the very poor and extremely poor category as shown in Fig 4 , so the fibre reinforced shotcrete and bolting of $9-15 \mathrm{~cm}$ length with the bolt spacing is $1.2 \mathrm{~m}$ to $1.5 \mathrm{~m}$ should be the required reinforcement provided in the tunnel.

\section{References}

BIS Codes: Guidelines for Classification System on Rock Mass, Part I- for Predicting Engineering Properties (RMR Method), Bureau of Indian Standards, New Delhi, India.

Barton, N., Lien R. and Lunde J. (1974) Engineering classification of rock masses for the design of rock support. Rock Mechanics, v. 6, pp. 189 - 236.

Bieniawski, Z. T. (1974) Geomechanics classification of rock masses and its application in tunlleling. Proceedings, 3rd International Congress on Rock Mechanics, ISRM, Denver, National Academy of Sciences, Washington, D,C., v. 2A, pp., 27-32.

Bieniawski, Z.T. (1989) Engineering Rock Mass Classifications. John Wiley, 251p.

Deere, D. U. (1968) Technical description of rock cores for engineering purposes. Felsmechamik and Ingeniurgeologic (Rock Mechanics and Engineering Geology). v.I, pp. 16-22.

Deere, D.U. (1968) Geological considerations. In: R.G. Stagg and D.C. Zeinkiewicz (eds.) Rock Mechanics in Engineering Practice, Willey, New York, pp. 1-20.

Grimstad, E. and Barton, N. (1993) Updating the Q-System for NMT. Proc. int. symp. on sprayed concretemodern use of wet mix sprayed concrete for underground support, Fagernes. Oslo: Norwegian Concrete Assn., pp. 46-66.

Kim,Seung-Ryull (2008) Some experience from the soft ground tunnelling in urban area. Seminar on "The State-of-the-art Technology and Experience on Geotechnical Engineering in Korea and Hong Kong”- 28 March 2008, Geotechnical Division, The Hong Kong Institution of Engineers.

Loannou, Photios G. (1987) Geologic prediction model for tunneling, Journal of Construction Engineering and Management, v. 113, no. 4, pp. 569-590. 
Palmstrom, A. (1982) The volumetric joint count- a useful and simple measure of the degree of rock jointing. Proc. $4^{\text {th }}$ congress International Association for Engineering Geology, Delhi, v. 5, pp. 221-228.

Palmstrom, A. (1996) Engineering geology and rock engineering applied in the design of Norwegian tunnels, Presented at the conference on tunnels for the third Millennium, Prievidza Slovakia, pp. 59-74.

Singh, B. and Goel, R.K. (1999) Rock mass classification: A practical approach in civil engineering. Elsevier science Ltd., Amsterdam, 267 p.

Shucai, Li, Shuchen, Li, Qingsong, Zhang, Yiguo, Xue, Bin, Liu, Maoxin, Su, Zhechao, Wang and Shugang, Wang (2010) Predicting geological hazards during tunnel construction. J. Rock Mechanics and Geotechnical Engineering, v. 2 (3), pp. 232-242.

(Received; 23.07.2015; Accepted: 10.01.2016) 